\title{
Effect of Pyraclostrobin Application on Viral and Bacterial Diseases of Tomato
}

\author{
Nicholas Skandalis, Anastasia Dimopoulou, Despoina Beri, Aliki Tzima, Ioanna Malandraki, and Ioannis Theologidis, Department of \\ Phytopathology, Benaki Phytopathological Institute, 14561 Kifissia, Athens, Greece; Stergios Bitivanos, BASF Hellas S.A., 15125 Maroussi, \\ Athens, Greece; Christina Varveri, Department of Phytopathology, Benaki Phytopathological Institute; Tassos Klitsinaris, BASF Hellas \\ S.A.; and Nikon Vassilakos, Department of Phytopathology, Benaki Phytopathological Institute
}

\begin{abstract}
Skandalis, N., Dimopoulou, A., Beri, D., Tzima, A., Malandraki, I., Theologidis, I., Bitivanos, S., Varveri, C., Klitsinaris, T., and Vassilakos, N. 2016. Effect of pyraclostrobin application on viral and bacterial diseases of tomato. Plant Dis. 100:1321-1330.

Quinone outside inhibitors (QoI) are powerful fungicides, which have been reported, additionally to their fungicide activity, to increase plant capacity to activate cellular defense responses and to promote plant growth. In this work, the effect of the QoI class fungicide pyraclostrobin was examined against Cucumber mosaic virus (CMV), Potato virus $Y$ (PVY) and Pseudomonas syringae pv. tomato in tomato plants following artificial inoculation of the plants with the pathogens. Under controlled

environmental conditions, pyraclostrobin delayed viral and bacterial disease development, even if $P$. syringae pv. tomato internal population levels were not affected significantly. In contrast, under field conditions in commercial greenhouses, a reduced CMV disease incidence throughout the tomato cultivation period was recorded. Gene expression analysis indicated an effect of pyraclostrobin application on tomato MAPKs transcript levels and a possible interference with plant stress responses.
\end{abstract}

Quinone outside inhibitors, also known as strobilurins, have become one of the most important classes of agricultural fungicides. Their wide range of activity relies on their ability to disrupt the energy cycle of the fungus by binding to the quinone outside ubiquinol oxidation center of the cytochrome bc1 complex (complex III) in the inner mitochondrial membrane (Bartlett et al. 2002; Herms et al. 2002). There is evidence that, in recommended doses, strobilurins can positively affect plant growth (Diaz-Espejo et al. 2012; Factor et al. 2011; Grossmann and Retzlaff 1997; Wu and von Tiedemann 2001).

In dicot crops, the effects of these fungicides on plant physiology can also result in increased resistance to viral and bacterial pathogens. In a previous study, the strobilurin class fungicide pyraclostrobin (also referred to as F500; BASF-SE) enhanced the resistance of tobacco plants against Tobacco mosaic virus (TMV) and elicited a faster accumulation of pathogenesis-related (PR) protein 1 in response to TMV infection (Herms et al. 2002). Moreover, in tobacco plants, pyraclostrobin reduced infection by the virulent wildfire Pseudomonas syringae pv. tabaci, which was correlated with decreased bacterial population. In contrast, the hypersensitive reaction (HR) induced by infection of the avirulent bacterium $P$. syringae pv. tomato was delayed on pyraclostrobin-treated tobacco plants, while the bacterial population was increased, possibly due to antagonism between the positive effect on plant physiology and the programmed cell death upon recognition (Herms et al. 2002). More recently, seed treatment of common bean with different formulations of strobilurins, including pyraclostrobin, resulted in

Current address of A. Tzima: Laboratory of Plant Pathology, Agricultural University of Athens, 75 Iera Odos, 11855 Athens, Greece.

Corresponding authors: N. Skandalis; E-mail: n.skandalis@bpi.gr; and N.Vassilakos; E-mail: n.vassilakos@bpi.gr

A. Dimopoulou and D. Beri contributed equally to this work.

*The $\boldsymbol{e}$-Xtra logo stands for "electronic extra" and indicates that two supplementary figures and two supplementary tables are published online.

Accepted for publication 5 February 2016.

http://dx.doi.org/10.1094/PDIS-10-15-1216-RE

(C) 2016 The American Phytopathological Society reduced incidence of Bean common mosaic virus (BCMV) in field and greenhouse conditions (Udayashankar et al. 2012).

Pyraclostrobin's positive effect on plant defense has been connected to priming. Priming has been proposed as a distinct form of induced resistance which is caused by a chemical or biotic stimulus. Priming involves accumulation of latent signaling proteins into cells that are not used until challenge exposure to stress. In subsequent exposure to biotic or abiotic stress, these dormant proteins are activated and initiate signal amplification, which leads primed plants to develop a faster immune response (Beckers and Conrath 2007; Conrath 2011). Beckers and coworkers (2009) showed that benzo(1,2,3,thiadiazole-7-carbothioic acid S-methyl ester (BTH)induced priming in Arabidopsis plants resulted in increased accumulation of MPK3 and MPK6 transcripts and their corresponding proteins in inactive forms. Upon challenge with a virulent $P$. syringae pv. maculicola strain, the two proteins were rapidly activated by phosphorylation, which was correlated with a strong induction of defense related genes and reduced internal pathogen population.

Despite the widespread use of pyraclostrobin as a fungicide, there is scarcity of information concerning its effect against pathogens other than fungi on economically important crops. Tomato (Solanum lycopersicum) is considered as one of the most important crops for the agricultural economy of Mediterranean countries. Current and emerging tomato diseases caused by viral or bacterial pathogens (www.eppo.int) can be devastating, causing severe economic losses in many crops, because they reduce yield and quality. The control of bacterial and viral diseases is more difficult compared with fungal diseases, and is usually based on crop rotation, use of resistant varieties, sanitation measures, disease exclusion, and control of vectors. Cucumber mosaic virus (CMV; genus Cucumovirus, family Bromoviridae) has probably the widest host range among viruses, including many crop species worldwide (Scholthof et al. 2011). In tomato, certain isolates of the virus can cause complete loss of production. Common disease syndromes include typical fernleaf-shoestring, tomato shrinkage, and lethal necrosis or tomato necrosis (Varveri and Boutsika 1999). Potato virus Y (PVY; genus Potyvirus, family Potyviridae) is the major viral threat of potato (S. tuberosum) (Scholthof et al. 2011); however, during the last decades, tomato and pepper PVY isolates inducing severe symptomatology have been reported in the Mediterranean region (Fanigliulo et al. 2005; Mascia et al. 2010). Moreover, mixed infection of PVY and CMV has also been recorded, especially in recent years, resulting in synergistic effects (Fukuzawa et al. 2010) (C. Varveri, unpublished). 
The main method of transmission of both CMV and PVY in nature is by a large number of aphid vector species in a nonpersistent manner. $P$. syringae pv. tomato, cause of bacterial speck of tomato, is considered one of the most important bacterial pathogens based on scientific and economic terms (Mansfield et al. 2012). The bacterium grows epiphytically and disease is favored by high leaf humidity and relatively low temperatures. Bacteria enter the intercellular spaces of leaves through natural openings such as stomata and wounds and multiply endophytically and, initially, asymptomatically, before the development of the characteristic necrotic and chlorotic lesions on the leaves (Mansfield et al. 2012). Therapeutic measures for bacterial diseases are limited to copper-based formulations, at least among European Union countries. However, legislation urges its reduced use and the development of copper-free crop production systems (Oger 2010).

In the present study, the effect of the strobilurin fungicide pyraclostrobin (F500) was assessed under controlled environmental conditions on tomato plant responses against CMV, PVY, and $P$. syringae pv. tomato. Moreover, the effect of pyraclostrobin was assessed against CMV in large-scale experiments carried out under field conditions, where plants are frequently exposed to several kinds of abiotic stress. The potential of pyraclostrobin to elicit defense responses was examined by quantifying the transcript levels of genes used as markers of direct defense responses and the priming mechanism.

\section{Materials and Methods}

Plant material and pathogens. Tomato plants (S. lycopersicum 'Belladonna F1') were used throughout this study. Viruses were the CMV tomato isolate CMV-4 and the PVY potato isolate PVY-1 from the Benaki Phytopathological Institute culture Collection (BPIC). Both viruses were maintained in tobacco plants (Nicotiana tabacum 'Samsun'). Bacterial strains included rifampicin-resistant $P$. syringae pv. tomato type strain DC3000 (Cuppels and Ainsworth 1995) and native strains BPIC 315 and BPIC 389 from BPIC. Strains were routinely grown on King's B (KB) medium (King et al. 1954), nutrient agar (NA) (Lapage et al. 1970), and Luria-Bertani (LB) broth. Cultures were grown for $24 \mathrm{~h}$ at $28^{\circ} \mathrm{C}$ under an appropriate concentration of antibiotic for selection, as applicable.

Pathogen inoculation assays. Viral inocula were prepared from CMV- or PVY-infected tobacco leaf tissues and ground in $10 \mathrm{mM}$ sodium phosphate and $0.2 \%$ (wt/vol) DIECA buffer $(\mathrm{pH} 7)$ in a $1: 3(\mathrm{wt} / \mathrm{vol})$ dilution containing $3 \%$ (wt/vol) active carbon and carborundum. Plants were rub inoculated with CMV or PVY inoculum onto one-half of a young, fully expanded composite leaf of each tomato plant. Inocula were also applied to local lesion hosts of CMV and PVY (Chenopodium quinoa and C. amaranticolor, respectively) to quantify the infectivity of each inoculum. The progress of viral infection was assessed both visually and by double-antibody sandwich enzyme-linked immunosorbent assay (ELISA) (Clark and Adams 1977) using CMV and PVY polyclonal antibodies (produced in-house and by LOEWE, respectively). ELISA was performed on samples consisting of tomato leaves homogenized in plastic bags $(1: 10$ [wt/vol]) in $0.5 \mathrm{M}$ trisodium citrate $(\mathrm{pH} 6.5)$ plus $0.1 \%$ thioglycolic acid. Samples were considered positives when their absorbance at $405 \mathrm{~nm}\left(\mathrm{~A}_{405}\right)$ was higher than 2.5 times the mean $\mathrm{A}_{405}$ of three healthy control samples (Mathews et al. 1997).

To prepare bacterial inocula, cultures were grown in $5 \mathrm{ml}$ of liquid LB medium; bacterial cells were then harvested by centrifugation at $2.800 \mathrm{rpm}$ for $10 \mathrm{~min}$ in $10^{\circ} \mathrm{C}$, washed twice in sterile $10 \mathrm{mM} \mathrm{MgCl}_{2}$ and finally resuspended at an optical density at $600 \mathrm{~nm}$ of 0.12 $\left(10^{8} \mathrm{CFU} \mathrm{m} l^{-1}\right)$ in $10 \mathrm{mM} \mathrm{MgCl}_{2}$. Spray inoculation was employed to simulate natural infection of tomato (Papadakis et al. 2015). The X77 (Loveland Inc.) spreading agent was added to the inocula and the upper and lower surface of tomato leaves were sprayed until run-off, using a hand-held pneumatic sprayer. Plants were inoculated at the developmental stage of fully developed first true leaves or the first visible primary apical side shoot (phenological developmental stages 104 or 201, respectively, according to Biologische Bundesantalt, Bundessortenamt and Chemische Industrie $[\mathrm{BBCH}]$ ranking). Disease incidence, bacterial population, and systemic acquired resistance induction were assessed in infected plants as described below.

Plant growth conditions. In experiments carried out under environmentally controlled conditions, plants were grown at 25 and $18^{\circ} \mathrm{C}$ (day and night, respectively) in an insect-proof greenhouse with a 16-h photoperiod. Additional daylight illumination was provided by standard mercury vapor reflector lamps (Sylvania HSR-BW400/4500K). Plants were potted in a mixture containing Klasmann Potgrond $\mathrm{P}$ blocking substrate and perlite (approximately 4:1). After the first 10 days from potting, supplementary fertilizer (Complesal 12-4-6 + micro; Aglukon) was used. Humidity was adjusted to approximately $90 \%$ using a Faran Cesio humidifier (Faran Industrial Ltd.) in bacterial disease experiments described below.

In field experiments, plants were grown in two high-tunnel greenhouses, used routinely for tomato fruit production in the area of Marathonas (Attica, Greece). High tunnels were covered by sheets of white plastic and had no side windows; ventilation was carried out solely from the two edges through insect-proof nets. This resulted in a temperature fluctuation between 20 and $48^{\circ} \mathrm{C}$ for the experiments initiated in the spring whereas, for the experiment started in late summer, lower temperatures were as low as $10^{\circ} \mathrm{C}$ during the second half of the experimental period. Tomato plants were grown in a nursery in conditions that differ from those mentioned above, in that plants were hardened for 10 days by a reduction in available water and treated with mancozeb M-45 $80 \mathrm{WP}$ (Mancozeb 80\% [wt/wt]), against field soilborne fungi. A twin-row planting system was used in high tunnels and plants were drip irrigated twice a day. A fertilization scheme including ENTEC balance and POLYPLANT and a crop protection program using STEWARD $30 \mathrm{WG}$ (indoxacarb $30 \%$ [wt/wt]), TOPAS $10 \mathrm{EC}(10 \% \mathrm{wt} / \mathrm{vol})$, and ALVERDE $24 \mathrm{SC}$ (metaflumizone $24.0 \%$ [wt/vol]), standard for tomato cultivation in the area, were followed.

Pyraclostrobin application. Pyraclostrobin in a commercially available formulation containing 20\% active ingredient F500 was provided by BASF-SE and used in the dosage for tomato recommended by the company (F-500 formulation at $0.8 \mathrm{ml} /$ liter of water). Plants were sprayed until run-off (maximum rate of application estimated up to $7 \mu \mathrm{l}$ of active ingredient per plant, depending on plant age; see below). The commercial F500 formulation lacking the active ingredient pyraclostrobin (henceforward designated as "blank formulation") was also provided by BASF and used at the same dilution as F500. Copper hydroxide (30.7\% [wt/wt]; KOCIDE $20 \mathrm{WP}$ ) was included as a reference standard for bacterial disease assays. Timing of treatments was based on the optimum differences between F500 treatment and control, obtained in preliminary experiments (data not shown). Thus, a two-application program was followed in all experiments assessing possible action of pyraclostrobin against viruses, which consisted of a first application 1 day before challenging the tomato plants with the virus (CMV or PVY) and a second 1 week later (6 days postinoculation [dpi]). Similarly, a two-application program was adopted in experiments assessing pyraclostrobin action on $P$. syringae pv. tomato, with the difference that the first application was performed 2 days before inoculation and the second 2 weeks later for experiments under controlled conditions or 40 days later for experiments under field conditions. Formulations were applied as aerosols until run-off using a 5-liter calibrated commercial sprayer (Epoca; ITA). Plants were then allowed to dry until no droplet was visible and returned to the incubation area.

Design and layout of viral disease experiments. To assess the effect of pyraclostrobin against plant viruses, two sets of experiments were carried out, one under controlled environmental conditions against CMV and PVY and the second under field conditions against CMV. In both cases, treatments consisted of (i) pyraclostrobin, (ii) blank formulation, and (iii) water, and were applied to tomato plants with fully developed first true leaves (BBCH stages 102 to 103).

Greenhouse experiments utilized a randomized complete block design with two blocks. Treatments were applied to plots consisting of 20 plants. Leaf sampling for examination of local and systemic infection started at $5 \mathrm{dpi}$ and was repeated every 2 to 4 days over a period of 3 weeks. Experiments were repeated twice. Gene expression 
analysis (see below) was performed simultaneously with the viral disease experiments under controlled conditions. Samples for gene expression were taken each time from intact plants, before sampling for ELISA, so that wounding would not induce abiotic stress reactions. For this reason, ELISA sampling at 5 dpi was performed on 13 plants per plot, leaving 7 plants intact for the gene expression sampling of $7 \mathrm{dpi}$.

In the case of experiments under field conditions, plants were transferred from the environmentally controlled greenhouse into the high-tunnel greenhouses 1 week after the second pyraclostrobin application. For assessment of pyraclostrobin effect on CMV infection, three different experiments were conducted (two were initialized in the spring and a third in late summer) and plants were monitored for approximately 75 dpi (60 days posttransplantation). Field experiments utilized a randomized complete block design with four blocks. Treatments were applied to plots consisting of 10 plants. Twelve untreated plants were placed between plots to monitor virus transmission. No virus spread was detected by ELISA or visual symptoms. Plant samples consisting of fully developed apical leaves detached from plants from all treatments and the negative controls were collected at approximately 20 and 50 to $60 \mathrm{dpi}$ and analyzed by ELISA.

Design and layout of bacterial disease experiments. The effect of pyraclostrobin against bacterial speck disease was evaluated under controlled environmental conditions and under field conditions.

Under controlled environmental conditions, two sets of tests were performed. Experiments were designed according to the European and Mediterranean Plant Protection Organization standards for efficacy evaluation of bactericides (www.eppo.int). Evaluation was based on disease development expressed as disease symptom severity and on internal pathogen population. Foliar disease severity was rated visually as a percentage of necrotic foliage (0 to $100 \%)$.

In the first set of tests, four treatments were assessed: F500, its blank formulation, a water treatment (mock), and a copper formulation. Plants at stage BBCH 104 were challenged with P. syringae pv. tomato $48 \mathrm{~h}$ after the first application of treatments. Disease development was assessed in two independent experiments, each organized in three blocks of four plots, one per treatment. Each plot numbered eight plants. Pathogen population growth was determined by cell counts in leaf disc samples taken at $12 \mathrm{~h}$ postinoculation (hpi) and 2, 5, 9, 12 (just before the second pyraclostrobin application), and 17 dpi. A single pooled sample was assembled per plot, consisting of three random samples taken from three different plants. Samples were extracted as 8-mm-diameter leaf discs that were surface sterilized for epiphytic bacteria. Samples were then homogenized in $10 \mathrm{mM} \mathrm{MgCl}$, and a $100-\mu \mathrm{l}$ aliquot of the homogenate was plated onto NA agar containing rifampicin and incubated for $48 \mathrm{~h}$ at $28^{\circ} \mathrm{C}$. At the end of the experiment (40 dpi), the internal (endophytic) $P$. syringae pv. tomato population in the phyllosphere was enumerated. In detail, all leaves were harvested and pooled samples of each experimental unit (plot) were immersed in $70 \%$ ethanol for $2 \mathrm{~min}$ for surface disinfection and then dried in a laminar flow hood at $24 \pm 1^{\circ} \mathrm{C}$ for $30 \mathrm{~min}$. Each sample was then divided in triplicate and cut to an appropriate size to fit into extraction bags (Bioreba AG, SWI) containing $10 \mathrm{ml}$ of $10 \mathrm{mM} \mathrm{MgCl}_{2}$. Samples were homogenized (HCT Shaping systems SA) and $P$. syringae pv. tomato cells were enumerated in 1-ml aliquots, as described above.

In the second set of tests, disease development was assessed at a larger scale, targeting the early stages of disease development and using larger plants (BBCH 201). The same application scheme was followed as in the first set of tests, with the difference that, in the later set, the blank formulation alone was considered as the negative control treatment and the water treatment was omitted. Three independent experiments were performed, each organized into three blocks of three plots, one per treatment. Plots numbered 10 plants, of which 4 leaves/plant were assessed, yielding a total of 1,080 leaves. Leaves were assessed for disease development and bacterial specks on new leaves were counted.

Under field conditions (in commercial high tunnels), the internal $P$. syringae pv. tomato population was assessed in two independent experiments, one held in spring and one in autumn. The first pyraclostrobin application was carried out at $\mathrm{BBCH} 104$ followed by inoculation with $P$. syringae pv. tomato after $48 \mathrm{~h}$. Plants were then transplanted into high tunnels at $7 \mathrm{dpi}$. The second pyraclostrobin application occurred at $40 \mathrm{dpi}$, at which point the plant phyllosphere was dense and lower leaves were susceptible to secondary $P$. syringae pv. tomato infection. Each experiment was organized in a randomized complete block design that was generated by the SPSS statistics software. The design included five blocks of four plots, one per treatment (F500, blank formulation, water, and copper). Treatments were applied to plots consisting of 10 plants in twin-row planting. Plots were separated by four guard plants. In total, 240 plants was used in each experiment. Pooled samples for each plot were collected twice, at $40 \mathrm{dpi}$ (right before the second application of treatments) and at 80 dpi. Each sample consisted of 10 lower leaves, which corresponded to an equal number of randomly selected plants. Samples were homogenized as mentioned before and $100-\mu l$ aliquots of serial dilutions were plated in triplicate on plates containing $\mathrm{KB}$ agar to allow for enumeration of fluorescent CFU under UV light after incubation for $48 \mathrm{~h}$ at $28^{\circ} \mathrm{C}$.

Gene expression analysis. The effect of pyraclostrobin on the tomato transcript levels of mitogen-activated protein kinases LeMPK1 and LeMPK3 (Kandoth et al. 2007; Mayrose et al. 2004), RNAdependent RNA polymerase 1 (RDR1) (Xie et al. 2001), PR proteins PR5 and PR1 (van Loon et al. 2006), and peroxidase PrxN1 (Moschou et al. 2009) was examined following time-course studies using quantitative reverse-transcription polymerase chain reaction (RT-qPCR). Gene-specific primers for each of the aforementioned genes were designed in this study, with the exception of PRI (Moschou et al. 2009). More specifically, LeMPK1 and LeMPK3 were identified as the tomato orthologous of the Arabidopsis mitogen-activated protein kinases 3 and 6 (AtMPK3 and AtMPKO), respectively, using the later as baits in the $S$. lycopersicum database (Sol genomic network; https://solgenomics.net). RDR1, PR5, and PrxN1 were also identified in Sol genomic network using the respective tobacco sequences as baits. The full-length coding DNA sequences (CDS) of each gene were retrieved from Sol genomic network and fully aligned using the ClustalW2 bioinformatics tool. Primers for RTqPCR were designed in the most dissimilar regions of the CDS sequences in order to increase specificity of the reaction. Transcript levels of the target genes were quantified relatively to ubiquitin using primers UBI3-F and UBI3-R (Rotenberg et al. 2006). Primer sequences are listed in Supplementary Table S1.

Three independent experiments were carried out to examine the effect of pyraclostrobin on gene expression of LeMPK1 and LeMPK3 in uninfected tomato plants. Plants were treated twice each with (i) pyraclostrobin, (ii) blank formulation, and (iii) water, with a week interval. Gene expression was examined at $6,24,48$, and $72 \mathrm{~h}$ post first spraying (hpfs) and at $24 \mathrm{~h}$ post second spraying (hpss). In addition, the effect of pyraclostrobin on the expression of $R D R I$ and $P R I$ was examined after challenging the plants with viruses during the two experiments under controlled conditions described above. In experiments with CMV, samples were collected at 24 and $48 \mathrm{hpi}$ and $7 \mathrm{dpi}$ and, in experiments with PVY, at $48 \mathrm{hpi}$ and $7 \mathrm{dpi}$ (time points of $24 \mathrm{hpi}, 48 \mathrm{hpi}$, and $7 \mathrm{dpi}$ correspond to 48 hpfs, 72 hpfs, and 24 hpss, respectively). Similarly, the effect of pyraclostrobin on the expression of LeMPK1, LeMPK3, PR5, $P R 1$, and PrxN1 was examined after plants were challenged with $P$. syringae pv. tomato during the experiments under controlled conditions. Samples were taken at 0, 24, and 48 hpi and 12, 13, and $14 \mathrm{dpi}$ (corresponding to 24, 48, and $72 \mathrm{hpfs}$ and 0,24 , and 48 hpss, respectively).

Plants were sampled once. Pooled leaf-disc samples were collected from up to four different plants per experimental plot, immediately frozen into liquid nitrogen, ground, and stored at $-80^{\circ} \mathrm{C}$ until use. Total RNA was extracted using TRI reagent (Ambion) according to the manufacturer's instructions. The concentration and purity of RNA were estimated using a P330 nanophotometer (IMPLEN). To remove traces of DNA, RNA extracts were treated with RNase-free DNase I (New England Biolabs). DNAse-treated 
RNA (400 ng) was reverse-transcribed into cDNA with Superscript II reverse transcription (Invitrogen Life Technologies Co.) using a mixture of oligo-dT as primers. qPCR was performed using $0.5 \mu \mathrm{l}$ of $5 \times$ water-diluted cDNA, $1 \mu \mathrm{M}$ each primer, and a commercial qPCR master mix kit (Applied Biosystems). Initially, cDNA was denatured by incubation at $95^{\circ} \mathrm{C}$ for $10 \mathrm{~min}$; amplification was at $95^{\circ} \mathrm{C}$ for $15 \mathrm{~s}$ and $60^{\circ} \mathrm{C}$ for $60 \mathrm{~s}$, repeated for 40 cycles. Reactions were performed in duplicate and results were analyzed with the StepOne Software v.2.2.2. The $2^{-\Delta \Delta \mathrm{Ct}}$ relative quantification method was used for data analysis (Livak and Schmittgen 2001; Pfaffl 2001). The average level of target values $\left(2^{-\Delta \Delta \mathrm{Ct}} \times 1,000\right)$ was calculated for each gene of interest on the basis of two or three independent biological samples. Reactions with no template verified the absence of contamination and primer dimer formation, while the absence of nonspecific products was confirmed by analysis of melting curves.

Data analysis. In the case of viral assessment, data were analyzed by applying generalized linear mixed-effects models (GLMM) fitted by maximum likelihood with binomial (logit-link) errors, because each observation point represented either the presence or the absence of infection. Time and treatment as well as their interaction were modeled as fixed factors and block was modeled as the random independent variable. In order to account for repeated measures, individual plants were nested within block in the random part of the models. Significance of responses was assessed with $z$-ratio tests. Calculations were done with the glmer function within the lme 4 package in $\mathrm{R}$ (Bates et al. 2015). Post hoc comparisons were done with Tukey tests and assuming Student $t$ distributions where the degrees of freedom were asymptotically determined, using the lsmeans package in $\mathrm{R}$.

In the case of bacterial assessment, the analysis of the data was performed by the application of linear mixed-effects models (LMM)

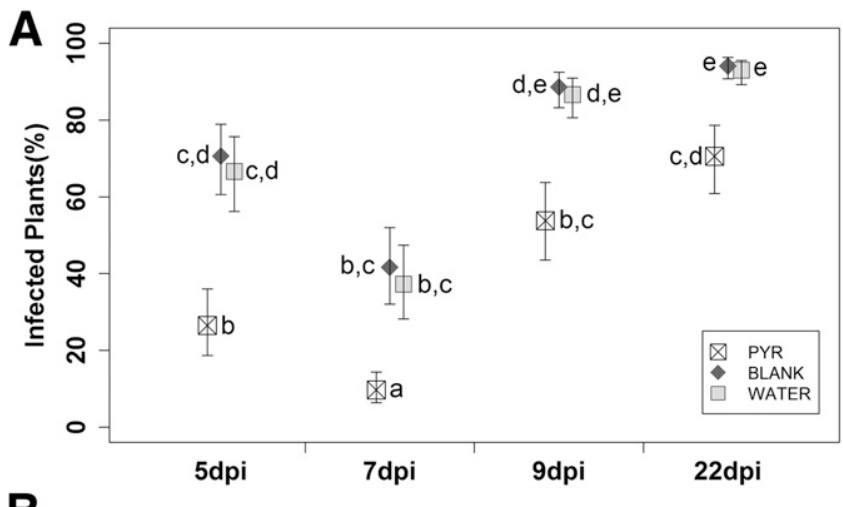

B

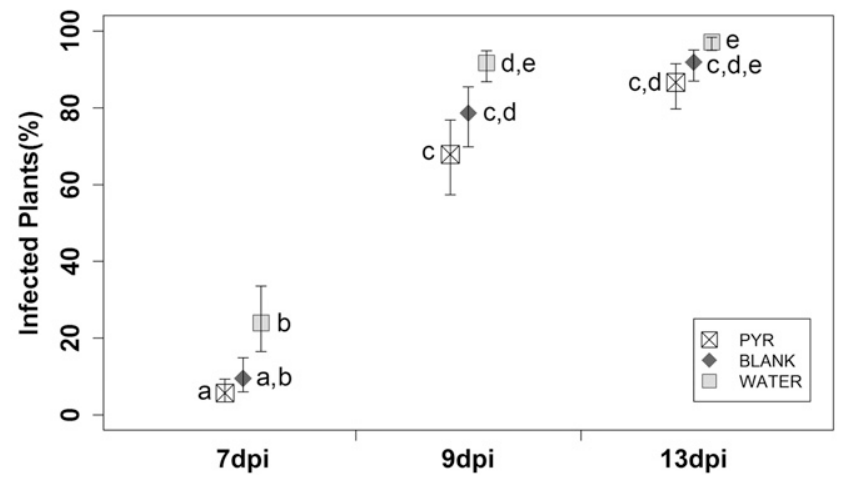

Fig. 1. Effect of pyraclostrobin on the progress of viral systemic infection in tomato plants under controlled conditions. Percentage (\%) of plants systemically infected with $\mathrm{A}$, Cucumber mosaic virus (CMV) and $\mathrm{B}$, Potato virus $\mathrm{Y}(\mathrm{PVY})$ after treatment with pyraclostrobin (PYR), blank formulation, or water over different time points. Treatments are indicated by different rectangle symbols. Combined results from two experiments are presented. Different letters represent statistically different data points at $P \leq 0.05$ according to Tukey post hoc comparisons. Ordinary leastsquare estimates are shown; $\mathrm{dpi}=$ days postinoculation. to arcsine-transformed data of disease development and GLMM with Poisson errors (log-link) to the counts of specs, both fitted by maximum likelihood. The functions lmer and glmer of the lme 4 package in $\mathrm{R}$ were used for calculations. Time after inoculation and treatment as well as their interaction were modeled as fixed factors, while plant individuals nested within block were the random independent variables. The $z$-ratio tests were used for testing the significance of responses and Tukey tests for post hoc comparisons. Internal pathogen growth was modeled using LMM to $\log _{10}$-transformed data (number of bacterial CFU) for each time point. Again, treatment was modeled as the main effect and block as random. Significance and post hoc tests were performed as above.

\section{Results}

Pyraclostrobin delayed CMV and PVY systemic infection under controlled conditions. In two independent experiments, CMV infection was examined both locally (in the inoculated leaves) and systemically (apical leaves) by ELISA. The analysis of inoculated leaves at 9 dpi showed that all tomato plants challenged with CMV were infected locally with the virus, regardless of the treatment applied (data not shown). However, at a systemic level, a reduced number of pyraclostrobin-treated plants were found infected compared with those of the other two treatments. Significant differences between pyraclostrobin and the other two treatments were recorded at all time points tested $(5,7,9$, and $22 \mathrm{dpi} ; P<0.001$ in all cases; Fig. 1A).

Similarly, in both experiments conducted to examine the effect of pyraclostrobin on PVY infection, no significant difference was recorded locally at 9 dpi because the $93 \%$ of tomato plants treated with pyraclostrobin or the blank formulation and the $89 \%$ of the plants treated with water were positive in ELISA tests (data not shown). At the systemic level, a delay in disease progress was observed in plants treated with pyraclostrobin up to the last time point tested (13 dpi). A statistically significant difference was recorded in the number of infected plants among pyraclostrobin treatment and water $(P<0.001$ in all cases, except $P<0.003$ for PVY versus PVY pyraclostrobin at 13 dpi; Fig. 1B). The blank formulation appeared to have a statistically significant intermediate effect in delaying PVY disease progress (Fig. 1B).

In agreement with the results obtained from the ELISA analysis, a delay of approximately 1 week was observed in symptom development in pyraclostrobin-treated plants which were found infected systemically. Plants infected with CMV started showing typical mosaic symptoms from 8 to $10 \mathrm{dpi}$ which progressed to light stunting and mild to medium leaf distortion. Similarly, PVY infection resulted in mosaic symptoms which first appeared at 10 to $14 \mathrm{dpi}$. No difference was recorded in symptom severity at 21 dpi among the three treatments for both viruses (data not shown).

Pyraclostrobin delayed bacterial speck disease development under controlled conditions. Plants infected with $P$. syringae pv. tomato under controlled conditions developed indistinct dark, round spots (specks) 5 to 7 days after spray inoculation. Pyraclostrobin application reduced disease development compared with the water treatment at $21 \mathrm{dpi}$ (Fig. 2A) and the difference was statistically significant $(P=0.001)$. Differences were not significant between pyraclostrobin and the blank formulation and between blank formulation and water treatment. Interestingly, disease development for pyraclostrobin treatment was comparable with that of copper treatment $(P=0.82)$. Symptom development at 60 dpi was similar for pyraclostrobin compared with blank and water treatment and between blank and water treatment. Disease development at 60 dpi remained at low levels following the copper treatment, and differences compared with pyraclostrobin, blank, or water treatments were statistically significant $(P \leq 0.0003$ in all cases).

Overall, the number of specks that developed on leaves which were not initially infected was low and, consequently, not significantly different among treatments for both time points (Fig. 2B). This was probably due to the inoculation of small plants that were suitable for long-term observations and the growth conditions that did not favor disease dispersal. 
Disease development was not affected significantly by time in the case of copper (it remained at low levels; Fig. 2A). Moreover, it was not affected by time in the case of blank or water treatments (higher levels). However, it was affected by time in the case of pyraclostrobin $(P=0.02)$, suggesting a delay in disease development. Therefore, it was decided to reevaluate a possible delay in disease development after pyraclostrobin application in a set of larger experiments. Based on the fact that both negative controls (water and blank) had a similar effect in the first set and that scores were lower in the case of blank formulation compared with water treatment, it was decided, for practical reasons, to use the blank formulation solely as negative control. The aim was to evaluate whether the nonsignificant statistical differences of pyraclostrobin compared with the blank formulation would change when plants were more suitable for infection. Thus, older plants were used, because they were more suitable for spray infection and would yield higher infection levels. In support of previous findings, early-stage disease development ( $7 \mathrm{dpi}$ ) was significantly delayed after pyraclostrobin application compared with the blank formulation $(P=0.01)$. Levels were comparable with those observed for the copper formulation $(P=0.71)$ (Fig. 2C). Similar statistical differences were obtained during the intermediate stages of disease development $(21 \mathrm{dpi})$ between pyraclostrobin and blank $(P=0.01)$ or copper $(P=0.89)$ treatments (Fig. $2 \mathrm{C})$.

Internal $P$. syringae pv. tomato population growth was not affected by pyraclostrobin. Internal $P$. syringae pv. tomato population was examined during the first set of experiments carried out under controlled conditions described previously, as well as in a group of experiments held under field conditions in high tunnels.

In experiments performed under controlled conditions, $P$. syringae pv. tomato cell counts did not yield a significant difference among pyraclostrobin, blank formulation, and water treatments during a 12-day span after spray inoculation (Fig. 2D). Statistical analyses for each time point and the overall course of population curves are presented in Supplementary Table S2A and B. Following the second application at $12 \mathrm{dpi}$, a differential effect of the four treatments was recorded; after blank or water applications, $P$. syringae pv. tomato population levels increased, probably due to the elevated humidity caused by spraying. In contrast, $P$. syringae pv. tomato populations remained unaltered after the second pyraclostrobin application and, noticeably, $P$. syringae pv. tomato levels were similar to those counted after the second copper application $(P=0.72)$. Nonetheless, differences were significant only when pyraclostrobin was compared with water treatment $(P<0.001)$ but not between pyraclostrobin and blank treatment. Significant statistical differences were observed in the case of copper compared with controls. As expected, bactericidal copper application 2 days before and 12 days after inoculation affected significantly the phyllosphere population levels, as reflected in the initial internal population counts $(0.5$ and $2 \mathrm{dpi})$ and the subsequent population growth (Fig. 2D). Finally, the total phyllosphere internal population at $38 \mathrm{dpi}$ was lower for copper $\left(6.2 \times 10^{5}\right.$ CFU/leaf disc) and pyraclostrobin $\left(6.3 \times 10^{5}\right.$ CFU/leaf disc $)$ compared with blank $\left(13.6 \times 10^{5} \mathrm{CFU} /\right.$ leaf disc $)$ and water $\left(9.9 \times 10^{5}\right.$ $\mathrm{CFU} / \mathrm{leaf}$ disc) treatments but differences were not statistically significant in the case of pyraclostrobin compared with controls. It was concluded that pathogen proliferation inside the plant tissue followed a similar course in all treatments except copper during a 38-day period following infection.

The course of $P$. syringae pv. tomato infection was also assessed in high tunnels in experiments performed in autumn and spring. Due to environmental conditions of exceptionally high temperatures and low humidity during spring, a substantial increase in internal $P$. syringae pv. tomato population was observed in tomato plants only during the autumn season. In support of previous findings, the average population size in lower tomato leaves did not differ significantly among treatments at 40 and 80 dpi (Supplementary Fig. S1). Nevertheless, a trend for lower population size was observed for pyraclostrobin compared with blank or water treatments. All examined plants were free of other pathogenic infection.

Pyraclostrobin reduced CMV incidence in tomato plants in high-tunnel greenhouses. To assess the effect of pyraclostrobin
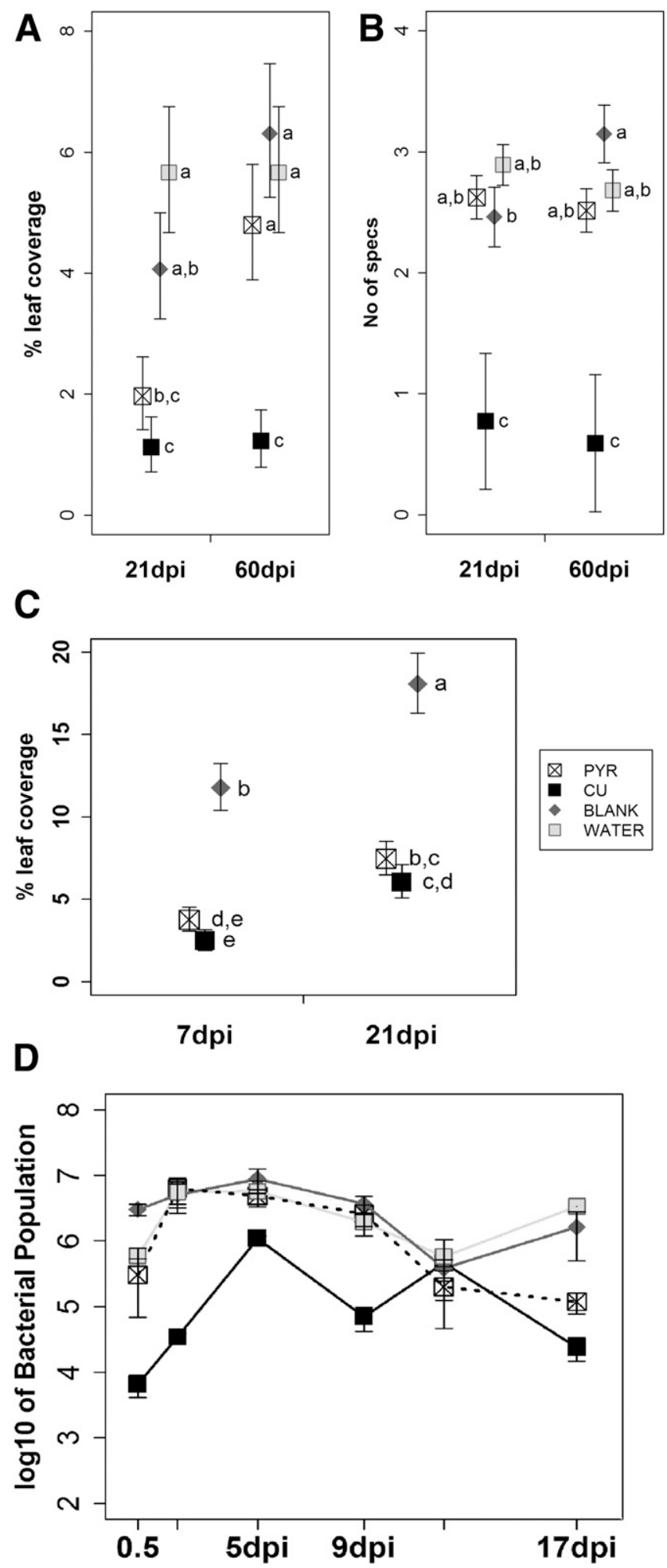

Fig. 2. Pyraclostrobin effect on bacterial speck disease development in tomato plants under controlled conditions. Disease development after spray inoculation with a Pseudomonas syringae pv. tomato DC3000 suspension at $10^{8} \mathrm{CFU} \mathrm{ml^{-1 }}$ on tomato plants treated with pyraclostrobin (PYR), its blank formulation, water, or copper hydroxide (reference standard). A, Disease development in infected leaves of younger plants and $\mathbf{B}$, number of specks in new leaves were recorded over different time points. Experiment was repeated once with similar results. $\mathbf{C}$, Disease development in infected leaves of older plants, assessed in three independent large-scale experiments ( $n=360$ per treatment). D, Increase in $P$. syringae pv. tomato population size as determined in leaf discs (in triplicate, pooled samples) over a 17-day time course following treatments and infection. Treatments are indicated by different rectangle symbols and bars represent estimated least-square means \pm standard error; Different letters indicate significant Tukey post hoc differences between treatments $(P \leq 0.05)$; dpi $=$ days postinoculation. 
on CMV infection, three experiments were carried out in high-tunnel greenhouses. In all cases, treatment with pyraclostrobin resulted in a reduced number of virus-infected plants (77 of 141 plants tested) throughout the tomato cultivation period compared with water treatments (138 of 146). When treatments of all three experiments were statistically analyzed, all treatments differed significantly, with the pyraclostrobin treatment leading to a $44.87 \%$ reduction (pyraclostrobin versus water, $P<0.0001$ ), whereas the blank formulation caused a $24 \%$ reduction in percentage of infected plants (blank versus water, $P=0.0012$; Fig. 3A). Noticeably, the number of infected plants did not change between the first ELISA analysis at $21 \mathrm{dpi}$ and the second contacted between 50 to 60 dpi. Symptomatology of the infected plants was similar regardless of the treatment applied, and consisted of mosaic and severe leaf distortion and stunting (Fig. 3B). The severe symptomatology was catholic, corresponding to all plants detected positive by ELISA, and apparent from 20 to $25 \mathrm{dpi}$, resulting in practically zero tomato fruit production. Accordingly, plants detected negative in ELISA showed a typical growth similar to that of uninoculated, negative control plants producing yield typical for the cultivar and region. Due to the pronounced difference in fruit production between CMV-infected and healthy plants, the effect of the applied treatments on yield was considered equivalent to the effect on disease incidence and it was not assessed further. Finally, regular visual examination of plants did not reveal the presence of plant pathogens (other than CMV) or pests.

Pyraclostrobin effect on LeMPK1 and LeMPK3 gene expression levels of uninfected plants. RT-qPCR analysis of the expression levels of LeMPK1 and LeMPK3 genes of uninfected tomato plants treated with pyraclostrobin, blank formulation, or water treatments showed no substantial differentiation among the three treatments at the examined time points of 24,48 , and $72 \mathrm{hpfs}$ (Fig. 4). However, an increase in transcript accumulation of approximately 1.5-fold for LeMPK1 and 2-fold for LeMPK3 was recorded at $6 \mathrm{hpfs}$ and $24 \mathrm{hpss}$ for pyraclostrobin-treated plants compared with plants treated only with water. Blank formulation also resulted in an increase of $1.75 \times$ in $L e M P K 3$ levels at $6 \mathrm{hpfs}$ compared with the water treatment (Fig. 4).

Pyraclostrobin effect on the expression level of genes correlated with biotic and abiotic stress responses in infected plants. Expression analysis during the experiments with CMV and PVY
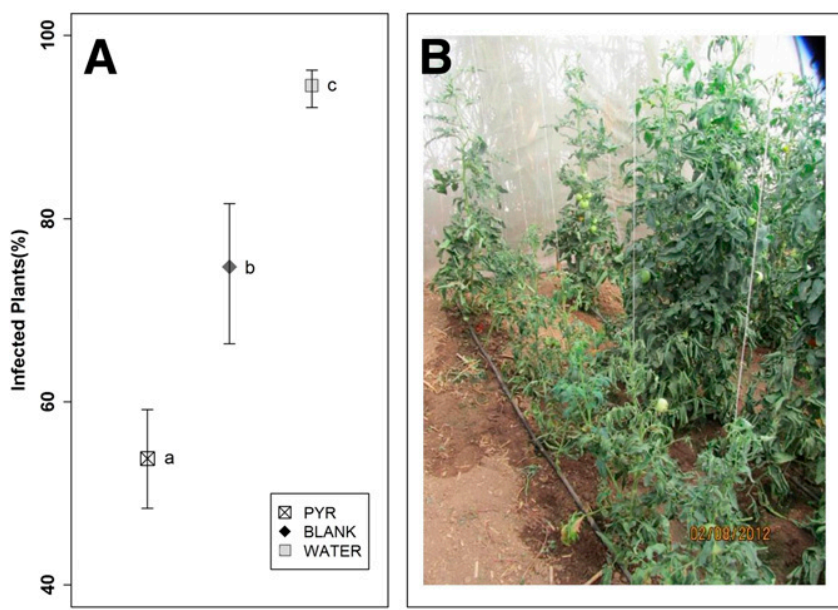

Fig. 3. Effect of pyraclostrobin on Cucumber mosaic virus (CMV) incidence in tomato plants under field conditions. A, Final percentage (\%) of tomato plants infected with CMV 50 to 60 days postinoculation after treatment with pyraclostrobin (PYR), blank formulation, or water in three different experiments conducted during different seasons. Combined results from three experiments are presented. Bars represent estimated least-square means \pm standard error. Different letters indicate significant Tukey post hoc differences between treatments $(P \leq 0.05)$. B, Differentiation in development between CMV-infected plants from a plot treated with pyraclostrobin (right row) and a plot treated with water (left row). Note the severe stunting of the later. Healthy guard plants are apparent at the end of each row. showed a similar induction of the expression of PRI and RDRI among the three treatments in samples taken from CMV inoculated leaves at 24 and $48 \mathrm{hpi}$, and in samples derived from apical leaves of plants inoculated with each of CMV and PVY at 48 hpi and 7 dpi (data not shown).

During the $P$. syringae pv. tomato infection, transcript levels of PR proteins PR5 and PR1 did not differentiate during the time course within and among pyraclostrobin, blank, and water treatments for samples collected at time points $0 \mathrm{hpi}$ (48 hpfs), $24 \mathrm{hpi}(72 \mathrm{hpfs})$, and $48 \mathrm{hpi}$ (96 hpfs). Results were similar for the time points examined following the second spraying $(0,24$, and $48 \mathrm{hpss})$, which occurred at 12 dpi (Supplementary Fig. S2). In contrast, LeMPK1 gene expression levels increased following infection, significantly in the case of blank and water treatments but not in the case of pyraclostrobin (Fig. 5A). Pyraclostrobin application attenuated the increase of LeMPK1 expression following P. syringae pv. tomato infection, and significant differences compared with blank and water treatment occurred at 24 hpi ( $t$ test $P<0.001$ in both cases). The relative increase of $L e M P K 1$ expression during the first 2 days after $P$. syringae pv. tomato inoculation (4 days after pyraclostrobin application) indicates that its induction is associated with the early stages of bacterial infection rather than application of treatments, for which a decrease after $24 \mathrm{~h}$ has been recorded in uninfected tissue (Fig. 4). Expression levels remained higher at $12 \mathrm{dpi}(0 \mathrm{hpss})$ and increased further following the second spraying in all treatments but less for pyraclostrobin compared with controls. A similar trend was observed for LeMPK3 gene expression in response to pyraclostrobin treatment: transcript levels were attenuated compared with blank and water treatments (Fig. 5B). Differences were significant compared with both controls at 0 hpss $(t$ test $P$ value $=$ 0.023 and 0.041 , respectively) and significant compared with water treatment at $48 \mathrm{hpss}(P=0.047)$. LeMPK3, to which woundinducing protein kinase properties have been attributed (Kandoth et al. 2007; Mayrose et al. 2004), was expressed in response to a slight wounding of the leaf surface to ease infection ( $0 \mathrm{hpi}$ [48 hpfs]). Transcript levels of the peroxidase PrxN1 were also found to be dependent on wounding stress or spraying; this is not unexpected and might be attributed to respiratory stress following the second spraying (Vergara et al. 2012). A trend for pyraclostrobin to attenuate such stress responses compared with both control treatments also was observed in the case of PrxN1.

\section{Discussion}

Despite the plethora of publications during the last decade dealing with the development of biotic or abiotic inducers of plant defenses against plant viruses and bacteria, known as plant activators, very few made it through the commercial product pipeline (Tampakaki et al. 2010). This is mainly due to the fact that successful plant activators, including $\mathrm{BTH}$ and $\mathrm{b}$-aminobutyric acid, have a negative effect on plant growth (Anfoka 2000; Dietrich et al. 2005). Instead, the industry largely relies on plant-growth-promoting rhizobacteria for the control of viral and bacterial diseases (Lugtenberg and Kamilova 2009).

The strobilurin-class fungicide pyraclostrobin has been shown before to interfere with plant defense against viral and bacterial pathogens in detached tobacco leaves and against BCMV in common bean (Herms et al. 2002; Udayashankar et al. 2012). In this study, the potential of pyraclostrobin was examined for the first time against viral diseases of tomato under both controlled and field conditions and against bacterial disease under conditions resembling natural infection.

Noticeably, a differentiation on the effect of pyraclostrobin against viral diseases was observed between experiments conducted under controlled conditions and those carried out under field conditions. During the first set of experiments, a delay in the progress of virus infection at the systemic level was recorded in pyraclostrobintreated plants compared with controls, although there was no difference among treatments for local infection. A possible practical significance of this delay in the field is related mainly to a decrease of virus load available to aphid vectors at the onset of the infection. A limited 
number of viruliferous winged aphid adults could result in a lower incidence of infected plants at the same time that plants are growing and becoming less sensitive to infection. Most importantly, in experiments conducted under field conditions, the pyraclostrobin-treated plants presented a $45 \%$ reduced disease incidence throughout the cultivation period. The establishment of an efficient recovery status at a later time point after CMV infection in pyraclostrobin-treated plants was not examined and, thus, cannot be ruled out as a possible reason

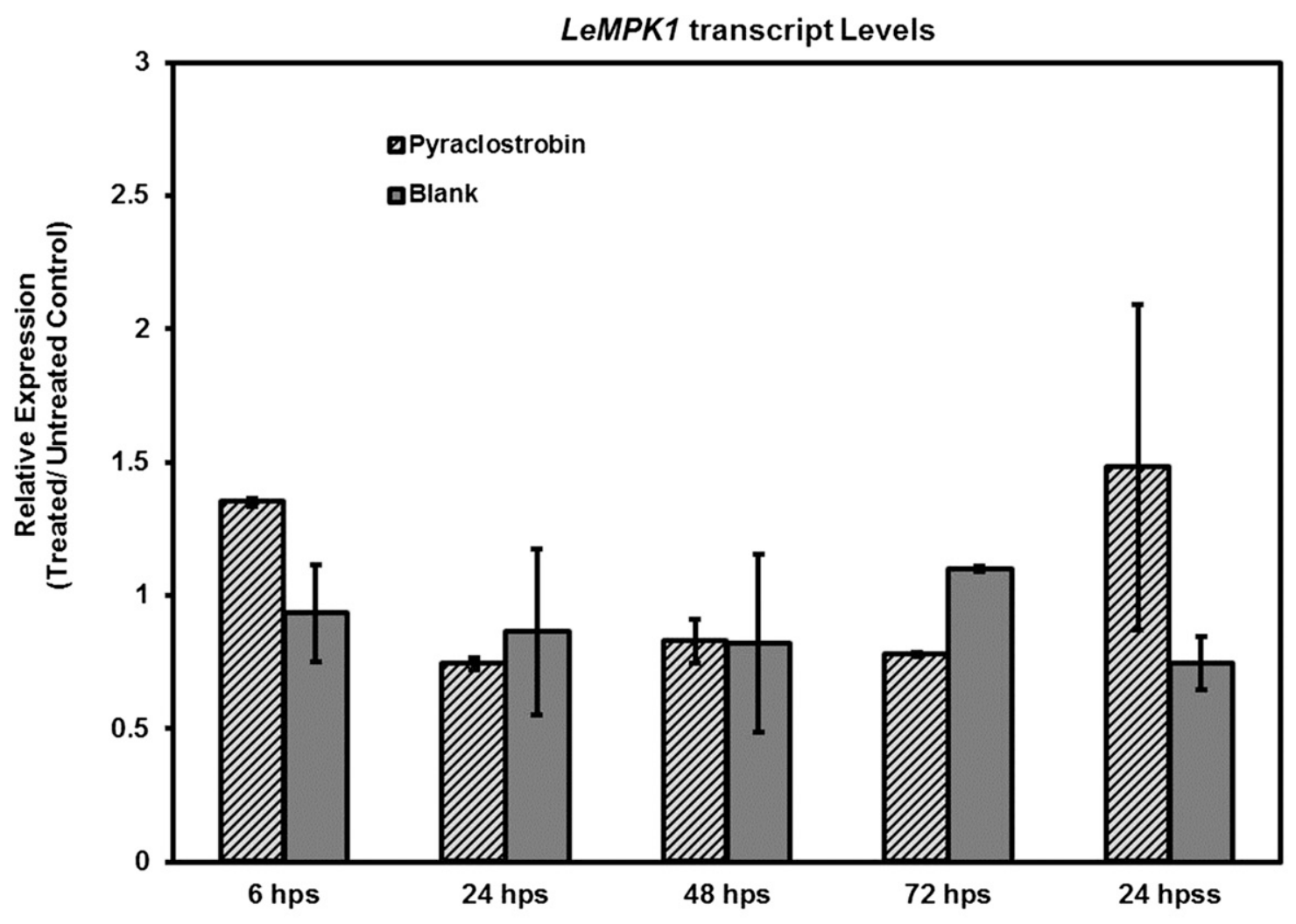

LeMPK3 transcript Levels

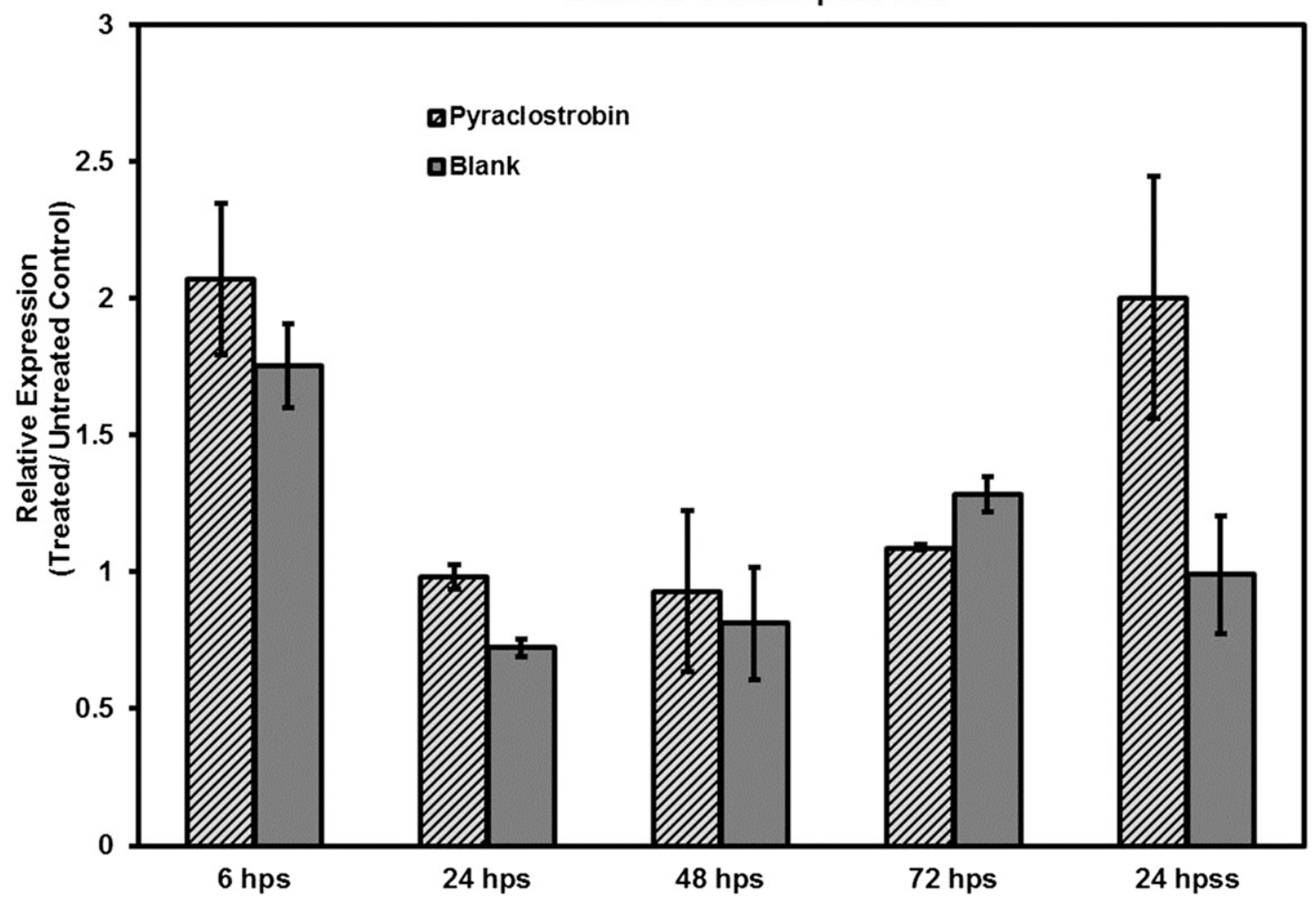

Fig. 4. Effect of pyraclostrobin on LeMPK1 and LeMPK3 relative expression levels of tomato plants at different hours after treatment with pyraclostrobin, blank formulation, or water (control). Pyraclostrobin and blank formulation treatments are presented in bars relative to water treatment, whose value was considered to be 1 . Averages of two or three independent biological samples are shown. Gene expression was normalized with the ubiquitin gene. Bars represent mean \pm standard error. 
for the difference in the results between the two sets of experiments, considering the cycling pattern of CMV titer during infection (Fukuzawa et al. 2010). However, a synergistic effect between pyraclostrobin and additional forms of stress that plants encountered in the experiments conducted in high tunnels such as transplantation shock and high temperatures is probably a more likely explanation for the significantly lower incidence of CMV infection observed. The latter hypothesis is in line with previous reports of positive effects of strobilurins in plant physiology (Grossmann et al. 1999; Ruske et al. 2003; Wu and von Tiedemann 2001).

The results obtained in high tunnels against CMV are in agreement with those reported by Udayashankar et al. (2012), where seed treatment with pyraclostrobin gave $65 \%$ protection of common bean against BCMV. Nevertheless, field experiments in which CMV spread will occur through its natural aphid vectors are needed in order to provide a solid argument for the positive effect of pyraclostrobin against CMV in tomato. Interestingly, a delay in systemic infection of PVY was also recorded in pyraclostrobin-treated plants under controlled environmental conditions although, previously, in a different experimental setting, pyraclostrobin failed to induce resistance against this virus (Herms et al. 2002). Therefore, PVY is an additional candidate for inclusion in field experiment studies. The blank formulation was found to confer some kind of protection against CMV in hightunnel experiments and against PVY under controlled conditions; however, a plausible explanation for these results cannot be provided.

Pyraclostrobin was evaluated against $P$. syringae $\mathrm{pv}$. tomato under conditions simulating natural bacterial infection in greenhouse crops and it was found to attenuate the appearance of disease symptoms in the early stages of infection of tomato plants. Its effect in assays simulating natural infection is similar to that reported by Herms and coworkers (2002) for pyraclostrobin application against the tobacco wildfire pathogen $P$. syringae pv. tabaci using leaf infiltration. Moreover, the delay in bacterial speck disease development in tomato plants that were in an ideal stage for $P$. syringae pv. tomato spray inoculation was comparable with that of the copper formulation, suggesting that pyraclostrobin application for protection against fungal pathogens might also have an additional effect on bacterial disease.

The mechanism by which pyraclostrobin affected tomato defense against the examined viruses and bacteria was investigated by examining the expression of a number of genes known to be involved in priming and biotic stress responses. Thus, the effect of pyraclostrobin in the expression levels of LeMPK1 and LeMPK3, the orthologous genes of which have been proposed as priming markers in Arabidopsis (Beckers et al. 2009), was examined at different time points. In the absence of pathogens, a 2-fold increase of transcript accumulation of $L e M P K 3$ and approximately 1.5 -fold for $L e M P K 1$ were recorded for both $6 \mathrm{hpfs}$ and $24 \mathrm{hpss}$ in plants treated with pyraclostrobin. It is difficult to attribute a biological significance to gene expression differences of this scale; however, the increase of LeMPK3 and LeMPK1 transcript levels, especially after the second pyraclostrobin spray, could be related to the positive effect that the latter had in delaying disease progress for both groups of pathogens tested. It is noted that the second application of pyraclostrobin was decided

A
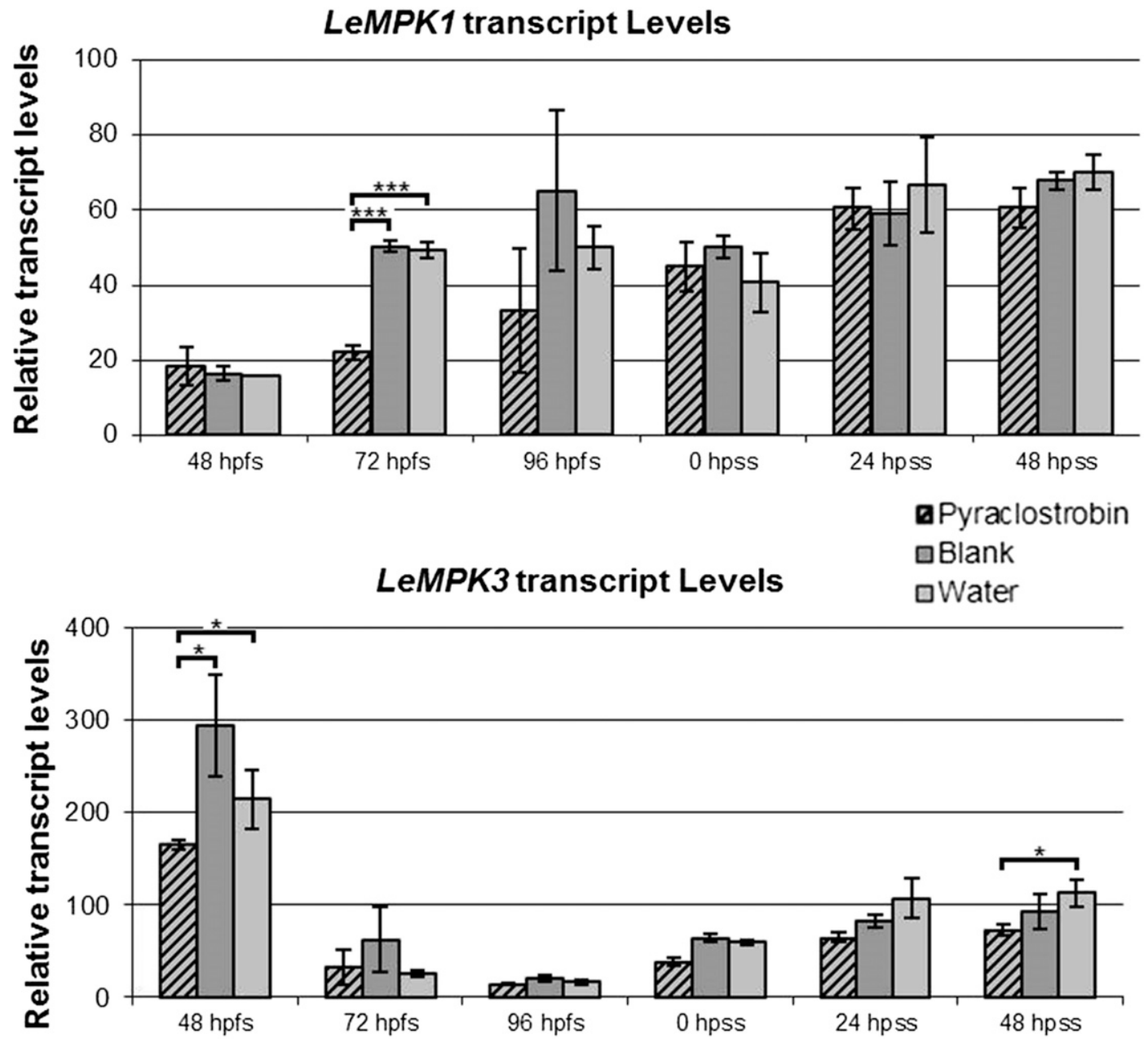

Fig. 5. Effect of pyraclostrobin on A, LeMPK1 and B, LeMPK3 gene expression of tomato plants at different hours after treatment with pyraclostrobin, blank formulation, or water (control) and inoculation with Pseudomonas syringae pv. tomato. Relative expression levels were attenuated in the case of pyraclostrobin compared with blank formulation or water (control) treatments. Time point $0 \mathrm{~h}$ postinoculation corresponds to $48 \mathrm{~h}$ post first spraying (hpfs) with treatments and 12 days postinoculation corresponds to $0 \mathrm{~h}$ post second spraying (hpss). Averages of two or three independent biological samples are shown. Gene expression was normalized with the ubiquitin gene. Bars represent mean \pm standard error; * and ${ }^{* *}$ indicate significant $t$-test differences between treatments $(P<0.05$ and 0.001 , respectively). 
after a series of preliminary experiments examining different time points of application (data not shown). Therefore, the possibility that, to some extent, pyraclostrobin affects the defense system of the plants through priming cannot be excluded, although further analysis of $L e M P K$ expression and activation at additional time points is required.

The antiviral effect of pyraclostrobin also could be based on its ability to trigger nitric oxide (NO) production in plant tissues (Conrath et al. 2004). Application of NO-releasing compounds has been related to enhancement of resistance against TMV and Potato virus $X$ in tobacco, which was correlated with an increase of PR1 accumulation (Li et al. 2014; Song and Goodman 2001). NO application has also been reported to result in induction of RDR1, which has an antiviral action (Hunter et al. 2013; Liao et al. 2013; Pandey and Baldwin 2007; Xu et al. 2013). However, analysis of transcript levels of $P R 1$ and $R D R 1$ of the plants inoculated with CMV and PVY during the experiments carried out under controlled conditions showed no difference in the induction of the expression of these genes among treatments at the specific time points examined. Similarly, during the assessment of pyraclostrobin against $P$. syringae pv. tomato infection under controlled conditions, similar levels of expression were recorded for $P R 1$ and $P R 5$ among treatments.

Monitoring of the internal population growth of $P$. syringae pv. tomato suggests that attenuation in symptom development following pyraclostrobin application does not correlate with lower internal pathogen population levels during the early stages of infection. This might also explain the "paradoxical result" reported by Helms and coworkers (2002), who found that pyraclostrobin reduced virulent pathogen population levels and symptom appearance in tobacco leaves while it increased population levels and delayed HR against avirulent pathogens. Pyraclostrobin was found to lower LeMAPK1 transcript levels compared with controls, especially at $24 \mathrm{hpi}$, in the presence of $P$. syringae pv. tomato. A similar effect was observed for LeMAPK3 during the inoculation process and a mild wounding, which was less evident as the infection progressed. It is noted that LeMPK are involved in abiotic stress responses, including wounding (Colcombet and Hirt 2008). The fact that pyraclostrobin also attenuated the elevation of PrxN1 expression in response to inoculation and spraying of plants suggests that pyraclostrobin might have a role in plant stress responses other than the defense induction.

To successfully colonize and infect plants, $P$. syringae pv. tomato is known to manipulate its gene regulation. Target genes differ from the onset of entry through wounds and stomata to establishment in the apoplast secretion of effector proteins (Brooks et al. 2005; Chen et al. 2007). Upregulation and activation of LeMPK1 and LeMPK3 are required for defense induction in effector-triggered immunity in tomato (del Pozo et al. 2004) but their expression is also upregulated by successful pathogen infection (Mayrose et al. 2004). In fact, Arabidopsis MPK3 (an ortholog of LeMPK1) has been suggested to promote $P$. syringae pv. tomato virulence and act as a negative regulator of inducible defenses, because an $m p k 3$ mutant displayed reduced susceptibility to $P$. syringae pv. tomato 3 days post spray inoculation (Frei dit Frey et al. 2014). This effect was less evident after infiltration. Such findings are in agreement with results in this study, in which the LeMPK1 gene is upregulated at 24 and $48 \mathrm{hpi}$, during the onset of infection. Therefore, it is suggested that LeMPK1 could, in fact, have a role in promoting $P$. syringae pv. tomato invasion in early stages of natural infection. This possibility has been disregarded thus far, because the role of LeMPK1 has been investigated mainly toward the induction of resistance and most assays have used inoculum infiltration in the apoplast, which triggered a rapid recognition or suppression interplay. Therefore, it is not unexpected that attenuated LeMPK1 transcript levels following pyraclostrobin treatment correspond to a delay in disease development.

Overall, pyraclostrobin application delayed disease development for both types of pathogens and reduced virus disease incidence. However, the mechanism by which this occurred is still not clear. Moreover, the results obtained need to be further verified in field experiments against additional combinations of pathogens and hosts, and perhaps by a meta-analysis on recorded bacterial and viral diseases on pyraclostrobin or other strobilurin fungicides trials against fungal diseases. Taking into consideration the lack of means for the control of viral and bacterial diseases in practice, the capacity of a secondary function of a widely applied fungicide against additional pathogen targets could be important for both economic and environmental reasons.

\section{Acknowledgments}

We thank P. Glynos, C. Panayotidi, and O. Kektsidou for technical assistance. This work was supported by BASF Hellas S.A. funds.

\section{Literature Cited}

Anfoka, G. H. 2000. Benzo-(1,2,3)-thiadiazole-7-carbothioic acid S-methyl ester induces systemic resistance in tomato (Lycopersicon esculentum Mill cv. Vollendung) to Cucumber mosaic virus. Crop Prot. 19:401-405.

Bartlett, D. W., Clough, J. M., Godwin, J. R., Hall, A. A., Hamer, M., and ParrDobrzanski, B. 2002. The strobilurin fungicides. Pest Manage. Sci. 58:649-662.

Bates, D., Maechler, M., Bolker, B., and Walker, S. 2015. Linear mixed-effects models using Eigen and S4. R Package, version 1.1-9. Online publication. https://cran.r-project.org/web/packages/lme4/index.html

Beckers, G. J. M., and Conrath, U. 2007. Priming for stress resistance: From the lab to the field. Curr. Opin. Plant Biol. 10:425-431.

Beckers, G. J. M., Jaskiewicz, M., Liu, Y., Underwood, W. R., He, S. Y., Zhang, S., and Conrath, U. 2009. Mitogen-activated protein kinases 3 and 6 are required for full priming of stress responses in Arabidopsis thaliana. Plant Cell 21:944-953.

Brooks, D. M., Bender, C. L., and Kunkel, B. N. 2005. The Pseudomonas syringae phytotoxin coronatine promotes virulence by overcoming salicylic aciddependent defences in Arabidopsis thaliana. Mol. Plant Pathol. 6:629-639.

Chen, Z., Agnew, J. L., Cohen, J. D., He, P., Shan, L., Sheen, J., and Kunkel, B. N 2007. Pseudomonas syringae type III effector AvrRpt2 alters Arabidopsis thaliana auxin physiology. Proc. Natl. Acad. Sci. USA 104:20131-20136.

Clark, M. F., and Adams, A. N. 1977. Characteristics of the microplate method of enzyme-linked immunosorbent assay for the detection of plant viruses. J. Gen. Virol. 34:475-483.

Colcombet, J., and Hirt, H. 2008. Arabidopsis MAPKs: A complex signalling network involved in multiple biological processes. Biochem. J. 413:217-226.

Conrath, U. 2011. Molecular aspects of defence priming. Trends Plant Sci. 16: 524-531.

Conrath, U., Amoroso, G., Köhle, H., and Sültemeyer, D. F. 2004. Non-invasive online detection of nitric oxide from plants and some other organisms by mass spectrometry. Plant J. 38:1015-1022.

Cuppels, D. A., and Ainsworth, T. 1995. Molecular and physiological characterization of Pseudomonas syringae pv. tomato and Pseudomonas syringae pv. maculicola strains that produce the phytotoxin coronatine. Appl. Environ. Microbiol. 61:3530-3536.

del Pozo, O., Pedley, K. F., and Martin, G. B. 2004. MAPKKK $\alpha$ is a positive regulator of cell death associated with both plant immunity and disease. EMBO J. 23:3072-3082.

Diaz-Espejo, A., Cuevas, M. V., Ribas-Carbo, M., Flexas, J., Martorell, S., and Fernández, J. E. 2012. The effect of strobilurins on leaf gas exchange, water use efficiency and ABA content in grapevine under field conditions. J. Plant Physiol. 169:379-386.

Dietrich, R., Ploss, K., and Heil, M. 2005. Growth responses and fitness costs after induction of pathogen resistance depend on environmental conditions. Plant Cell Environ. 28:211-222.

Factor, T. L., Júnior, S. L., Purquerio, L. F. V., and Calori, A. H. 2011. Secondary effects of fungicides in tomato seedlings production. Acta Hortic. 923:269-275.

Fanigliulo, A., Comes, S., Pacella, R., Harrach, B., Martin, D. P., and Crescenzi, A 2005. Characterisation of Potato virus Y nnp strain inducing veinal necrosis in pepper: A naturally occurring recombinant strain of PVY. Arch. Virol. 150: 709-20.

Frei dit Frey, N., Garcia, A., Bigeard, J., Zaag, R., Bueso, E., Garmier, M., Pateyron, S., De Tauzia-Moreau, M.-L., Brunaud, V., Balzergue, S., Colcombet, J., Aubourg, S., Martin-Magniette, M.-L., and Hirt, H. 2014. Functional analysis of Arabidopsis immune-related MAPKs uncovers a role for MPK3 as negative regulator of inducible defences. Genome Biol. 15:R87.

Fukuzawa, N., Itchoda, N., Ishihara, T., Goto, K., Masuta, C., and Matsumura, T. 2010. HC-Pro, a potyvirus RNA silencing suppressor, cancels cycling of Cucumber mosaic virus in Nicotiana benthamiana plants. Virus Genes 40: 440-446.

Grossmann, K., Kwiatkowski, J., and Caspar, G. 1999. Regulation of phytohormone levels, leaf senescence and transpiration by the strobilurin Kresoxim-methyl in wheat (Triticum aestivum). J. Plant Physiol. 154:805-808.

Grossmann, K., and Retzlaff, G. 1997. Bioregulatory effects of the fungicidal strobilurin Kresoxim-methyl in wheat (Triticum aestivum). Pestic. Sci. 50:11-20.

Herms, S., Seehaus, K., Koehle, H., and Conrath, U. 2002. A strobilurin fungicide enhances the resistance of tobacco against Tobacco mosaic virus and Pseudomonas syringae pv. tabaci. Plant Physiol. 130:120-127. 
Hunter, L. J. R., Westwood, J. H., Heath, G., Macaulay, K., Smith, A. G., Macfarlane, S. A., Palukaitis, P., and Carr, J. P. 2013. Regulation of RNAdependent RNA polymerase 1 and isochorismate synthase gene expression in Arabidopsis. PLoS One 8:e66530.

Kandoth, P. K., Ranf, S., Pancholi, S. S., Jayanty, S., Walla, M. D., Miller, W., Howe, G. A., Lincoln, D. E., and Stratmann, J. W. 2007. Tomato MAPKs LeMPK1, LeMPK2, and LeMPK3 function in the systemin-mediated defense response against herbivorous insects. Proc. Natl. Acad. Sci. USA 104:12205-12210.

King, E., Ward, M., and Raney, D. 1954. Two simple media fro the demonstration of phycocyanin and fluorescein. J. Lab. Clin. Med. 44:301-307.

Lapage, S. P., Shelton, J. E., and Mitchell, T. G. 1970. Nutrient agar. Page 116 in: Methods in Microbiology, Vol. 3A. J. R. Norris and D. W. Ribbons, eds. Academic Press, Ltd., London.

Li, Z., Liang, W.-S., and Carr, J. P. 2014. Effects of modifying alternative respiration on nitric oxide-induced virus resistance and PR1 protein accumulation. J. Gen. Virol. 95:2075-2081

Liao, Y.-W.-K., Sun, Z.-H., Zhou, Y.-H., Shi, K., Li, X., Zhang, G.-Q., Xia, X.-J., Chen, Z.-X., and Yu, J.-Q. 2013. The role of hydrogen peroxide and nitric oxide in the induction of plant-encoded RNA-dependent RNA polymerase 1 in the basal defense against Tobacco mosaic virus. PLoS One 8:e76090.

Livak, K. J., and Schmittgen, T. D. 2001. Analysis of relative gene expression data using real-time quantitative PCR and the $2^{-\Delta \Delta \mathrm{CT}}$ method. Methods 25:402-408.

Lugtenberg, B., and Kamilova, F. 2009. Plant-growth-promoting rhizobacteria. Annu. Rev. Microbiol. 63:541-556.

Mansfield, J., Genin, S., Magori, S., Citovsky, V., Sriariyanum, M., Ronald, P., Dow, M. X., Verdier, V., Beer, S. V., Machado, M. A., Toth, I. N., Salmond, G., and Foster, G. D. 2012. Top 10 plant pathogenic bacteria in molecular plant pathology. Mol. Plant Pathol. 13:614-629.

Mascia, T., Finetti-Sialer, M. M., Cillo, F., and Gallitelli, D. 2010. Biological and molecular characterization of a recombinant isolate of Potato virus $Y$ associated with a tomato necrotic disease occurring in Italy. J. Plant Pathol. 92:131-138.

Mathews, D. M., Riley, K., and Dodds, J. A. 1997. Comparison of detection methods for citrus tristeza virus in field trees during months of nonoptimal titer. Plant Dis. 81:525-529.

Mayrose, M., Bonshtien, A., and Sessa, G. 2004. LeMPK3 is a mitogen-activated protein kinase with dual specificity induced during tomato defense and wounding responses. J. Biol. Chem. 279:14819-14827.

Moschou, P. N., Sarris, P. F., Skandalis, N., Andriopoulou, A. H., Paschalidis, K. A., Panopoulos, N. J., and Roubelakis-Angelakis, K. A. 2009. Engineered polyamine catabolism preinduces tolerance of tobacco to bacteria and oomycetes. Plant Physiol. 149:1970-1981.

Oger, L. 2010. Directive 2009/128/EC on sustainable use of pesticides. CEUREG Forum XIV. Online publication. European Crop Protection Association. http:// www.ceureg.com/14/docs/presentations/Session_II_2_Laurent_OGER.pdf
Pandey, S. P., and Baldwin, I. T. 2007. RNA-directed RNA polymerase 1 (RdR1) mediates the resistance of Nicotiana attenuata to herbivore attack in nature. Plant J. 50:40-53.

Papadakis, G., Skandalis, N., Dimopoulou, A., Glynos, P., and Gizeli, E. 2015. Bacteria murmur: Application of an acoustic biosensor for plant pathogen detection. PLoS One 10:e0132773.

Pfaffl, M. W. 2001. A new mathematical model for relative quantification in realtime RT-PCR. Nucleic Acids Res. 29:e45.

Rotenberg, D., Thompson, T. S., German, T. L., and Willis, D. K. 2006. Methods for effective real-time RT-PCR analysis of virus-induced gene silencing. J. Virol. Methods 138:49-59.

Ruske, R. E., Gooding, M. J., and Jones, S. A. 2003. The effects of triazole and strobilurin fungicide programmes on nitrogen uptake, partitioning, remobilization and grain N accumulation in winter wheat cultivars. J. Agric. Sci. 140:395-407.

Scholthof, K.-B. G., Adkins, S., Czosnek, H., Palukaitis, P., Jacquot, E., Hohn, T., Hohn, B., Saunders, K., Candresse, T., Ahlquist, P., Hemenway, C., and Foster, G. D. 2011. Top 10 plant viruses in molecular plant pathology. Mol. Plant Pathol. 12:938-954.

Song, F., and Goodman, R. M. 2001. Activity of nitric oxide is dependent on, but is partially required for function of, salicylic acid in the signaling pathway in tobacco systemic acquired resistance. Mol. Plant-Microbe Interact. 14: 1458-1462.

Tampakaki, A. P., Skandalis, N., Gazi, A. D., Bastaki, M. N., Panagiotis, F. S., Charova, S. N., Kokkinidis, M., and Panopoulos, N. J. 2010. Playing the "Harp": Evolution of our understanding of hrp/hrc genes. Annu. Rev. Phytopathol. 48:347-370.

Udayashankar, A. C., Nayaka, C. S., Archana, B., Nayak, U., Niranjana, S. R., and Prakash, H. S. 2012. Strobilurins seed treatment enhances resistance of common bean against Bean common mosaic virus. J. Phytopathol. 160: 710-716.

van Loon, L. C., Rep, M., and Pieterse, C. M. 2006. Significance of inducible defense-related proteins in infected plants. Annu. Rev. Phytopathol. 44:135-62.

Varveri, C., and Boutsika, K. 1999. Characterization of cucumber mosaic cucumovirus isolates in Greece. Plant Pathol. 48:95-100.

Vergara, R., Parada, F., Rubio, S., and Pérez, F. J. 2012. Hypoxia induces H2O2 production and activates antioxidant defence system in grapevine buds through mediation of $\mathrm{H} 2 \mathrm{O} 2$ and ethylene. J. Exp. Bot. 63:4123-4131.

Wu, Y.-X., and von Tiedemann, A. 2001. Physiological effects of azoxystrobin and epoxiconazole on senescence and the oxidative status of wheat. Pestic. Biochem. Physiol. 71:1-10.

Xie, Z., Fan, B., Chen, C., and Chen, Z. 2001. An important role of an inducible RNA-dependent RNA polymerase in plant antiviral defense. Proc. Natl. Acad. Sci. USA 98:6516-6521.

Xu, T., Zhang, L., Zhen, J., Fan, Y., Zhang, C., and Wang, L. 2013. Expressional and regulatory characterization of Arabidopsis RNA-dependent RNA polymerase 1. Planta 237:1561-9. 